Doi: https://doi.org/10.17398/2340-4256.16.127

\title{
DEL ISLAM AL CATOLICISMO: EL GRAN PRÍNCIPE DE FEZ DEN- TRO DE LAS COMEDIAS DE CONVERSOS DE CALDERÓN*
}

\section{FROM ISLAM TO CATHOLICISM: EL GRAN PRÍNCIPE DE FEZ WITHIN CALDERÓN'S PLAYS OF CONVERTS}

\author{
FERNANDO RODRÍGUEZ-GALLEGO \\ Universitat de les Illes Balears-IEHM
}

\section{RESUMEN}

El gran príncipe de Fez es una obra de Calderón que dramatiza un perfil espiritual de importancia en la España y la Europa de la época: el converso. Ninguneada por Menéndez Pelayo, Wardropper la estudió dentro de las comedias religiosas de Calderón, pero la incluyó en un grupo que consideramos poco adecuado. Por ello, en este artículo se pretende demostrar que conforma, junto con El José de las mujeres, Los dos amantes del cielo y El mágico prodigioso, una traza de perfiles bien definidos, la de la conversión al cristianismo de un intelectual no cristiano, lo que permite resituar su lugar dentro de la obra de Calderón.

* Este trabajo se ha visto beneficiado de mi participación en los proyectos de investigación con referencias PGC2018-094395-B-I00, PGC2018-096004-A-I00 y PID2019-104045GA-C55, financiados por MCIN/AEI/10.13039/501100011033 y FEDER. Agradezco a Paula Casariego su atenta lectura de una primera versión del artículo; la responsabilidad sobre el resultado final es exclusivamente mía. 
Palabras clave: Calderón de la Barca, El gran príncipe de Fez, conversión, traza

\section{ABSTRACT}

El gran príncipe de Fez is a play written by Calderón that dramatizes an important spiritual profile of that time in Spain and Europe: the convert. Underappreciated by Menéndez Pelayo, Wardropper studied it within Calderón's religious plays, but included it in a group that we consider inappropriate. For this reason, this article aims to show that, together with El José de las mujeres, Los dos amantes del cielo and El mágico prodigioso, it constitutes a microgenre of well-defined profiles, that of the conversion to Christianity of a non-Christian intellectual, what allows us to replace it within Calderón's theatre.

Keywords: Calderón de la Barca, El gran príncipe de Fez, conversion, microgenre.

El gran príncipe de Fez no se cuenta entre las obras de Calderón de la Barca más atendidas por la crítica. En gran parte, tal situación probablemente se deba al duro juicio emitido en su día por Marcelino Menéndez Pelayo, quien desdeñó la comedia y no la tuvo en cuenta al estudiar las comedias religiosas de Calderón. Sin embargo, consideramos que la obra reviste gran interés y remite a un perfil espiritual de importancia en la España y la Europa de la época: el converso, en este caso un personaje de alta alcurnia que, en apariencia, no toma su decisión por motivos interesados, sino que lo hace en conciencia, tras una serie de dudas y a partir de una experiencia decisiva relacionada con su fe religiosa (Alonso Acero 2006).

Calderón toma el protagonista de su comedia de la realidad histórica del momento, pues construye su obra a partir de la conversión al catolicismo del príncipe de Fez Mohammed el-Attaz (Muley Mahomet en el texto de Calderón), quien, camino de La Meca, había sido hecho prisionero por los caballeros de Malta y había pasado cinco años en cautiverio hasta que se pagó su rescate. Sin embargo, tras una aparición milagrosa de la Virgen durante una tormenta al salir de Malta, decide volver y convertirse al cristianismo, y, tras ser bautizado, adopta el nombre de Baltasar de Loyola (Colombo 2013).

A Calderón, sin embargo, el personaje no le interesará por su biografía extraordinaria, o no solo, sino que lo amoldará a un patrón que ya había ensayado en otras obras ambientadas en los primeros años del cristianismo: el del personaje intelectual que, perteneciendo ya a una determinada religión, llega a la 
cristiana, en un primer momento a partir de su propia reflexión, aunque se convierta finalmente después de asistir a un prodigio. Calderón, así, entrelaza figuras de momentos históricos diferentes, unas legendarias o ficticias, otras construidas a partir de personas reales, y las relaciona a través de su teatro. Por ello, en este artículo nos proponemos estudiar el perfil espiritual del príncipe de Fez calderoniano dentro de un esquema constructivo o traza de gran fecundidad en el teatro religioso del autor.

Como decíamos, Menéndez Pelayo $(1941,172)$ desdeñó El gran príncipe de Fez y no la tuvo en cuenta en su estudio de las comedias religiosas de Calderón, en el que distinguió, a partir del asunto, tres grupos. Años más tarde, Bruce Wardropper les dedicó un importante trabajo en el que amplía y profundiza la clasificación propuesta por don Marcelino y añade un cuarto grupo, que denomina "comedias de la era cristiana", construidas en torno a "sucesos dilucidados de la historia cristiana" y en el que incluye tres comedias que no habían sido tratadas por el santanderino: La exaltación de la cruz, Origen, pérdida y restauración de la virgen del Sagrario y El gran príncipe de Fez. Wardropper entiende que en las tres "se hace hincapié en el significado espiritual de unos hechos históricos. Se compenetran lo histórico y lo sobrenatural: en cada obra, en lo demás verosímil, aparecen unas figuras sobrenaturales, aunque no sean más que unos ángeles" $(2000,730)$. Sin embargo, creemos que Wardropper no acertó a la hora de encuadrar El gran príncipe en este grupo, pues consideramos que estos lazos que establece el estudioso son endebles y más bien anecdóticos, pues no determinan la configuración dramática de estas piezas, muy diferentes entre sí.

En su "Estudio crítico sobre Calderón", Menéndez Pelayo había distinguido un conjunto de comedias religiosas que

tienen cierta unidad de pensamiento, y aun escenas muy semejantes: El José de las mujeres, Los dos amantes del cielo y El mágico prodigioso. En las tres los protagonistas son catecúmenos, y en las tres empiezan a salir de las tinieblas del paganismo por medio de la lectura de algún texto sagrado o profano [...]. En las tres combaten los protagonistas, ayudados por la gracia divina, contra los halagos del amor profano y contra todas las artes diabólicas, puestas en juego por el mismo príncipe de los abismos, que es personaje muy principal en ellas. $\mathrm{Y}$ en las tres, finalmente, reciben victoriosos la palma 
triunfal del martirio. Abundan en todos estos dramas, lo mismo que en los autos, las discusiones teológicas $(1941,338)^{1}$.

Wardropper mantuvo este grupo de comedias de "conversión de un pagano en santo cristiano" (2000, 734), en el que solo tiene en cuenta El mágico prodigioso, Los dos amantes del cielo y El José de las mujeres ${ }^{2}$ (en adelante, Mágico, Amantes y José), y ya del minucioso examen que les dedica se evidencia que es este el grupo en el que debe incluirse El gran príncipe de Fez (en adelante, Príncipe), pues, de acuerdo con Wardropper,

en estas comedias la estructura del argumento es la de una demanda espiritual. En los primeros siglos del Imperio Romano, un noble gentil erudito - que puede ser una mujer - encuentra, al parecer casualmente, un texto que le hace dudar del panteón autorizado y buscar al Dios único. El Demonio, armado de una licencia divina, trata de estorbar la búsqueda por medio de engaños $(2000,734)^{3}$.

Y este es exactamente el esquema de Príncipe, solo que cambiando la ambientación (el siglo XVII en lugar de los primeros siglos del Imperio Romano), de manera que el protagonista, en lugar de "gentil", es musulmán, diferencia que nos parece de poco peso a la hora de establecer el esquema dramático de la pieza, pues lo fundamental será su conversión al cristianismo a partir de un texto que le hace dudar, y a pesar de los intentos del demonio de estorbar su búsqueda del dios verdadero.

Wardropper, además, indica cómo en dos de estas comedias, Amantes y José, "el poder del Demonio queda contrapesado por el de espíritus buenos"

1 En su conferencia cuarta dedicada a Calderón, Menéndez Pelayo ya había reunido las tres comedias citadas en un grupo cuyo punto de partida "es un filósofo pagano que, por medio de la luz de la razón y del entendimiento discursivo, ha recibido cierta preparación evangélica, hasta levantarse a la comprensión del principio de la unidad de Dios, y dudar por lo menos de las fábulas del politeísmo" (1941, 170). En su "Estudio crítico" don Marcelino dejó fuera Las cadenas del demonio, que en su "Conferencia cuarta" juntó a las tres comedias ya mencionadas, pues a ellas se parece "en algunos detalles" (1941, 173 y 175).

2 Excluye Las cadenas del demonio por considerarla obra "probablemente apócrifa y que de todas formas queda al margen de mi definición del subgénero" (2000, 730-731). No hay razón para dudar de la autoría calderoniana (Vega García-Luengos 2008, 259-262; Coenen 2009, 114-119), pero, por sus peculiaridades, que la alejan de las otras obras de este grupo, la dejaremos fuera de este estudio.

3 La división establecida por Wardropper fue mantenida por Aparicio Maydeu (1992, 202-203, y 1999, 73-76), que incluye las tres comedias mencionadas en una "trilogía de la conversión” en la que señala los siguientes cinco "puntos de inflexión concretos en el desarrollo escénico": a) el docto pagano aparece solo en escena, rodeado de libros y estudiándolos; b) interrumpen las deliberaciones del docto pagano dos fuerzas contrapuestas: el Demonio y un emisario del Dios cristiano; c) una escena individualiza al docto pagano aislándolo de un contexto que le es hostil; d) el pagano convertido sufre martirio por profesar la fe en el Dios cristiano, y e) apoteosis final. 
(2000, 737), como sucede en Príncipe, de igual manera que "Con el tiempo la búsqueda intelectual se hace activa: el gentil se convierte al cristianismo, confiesa públicamente al Dios cristiano, y sufre el martirio" (2000, 734), como también ocurre en Príncipe, cuyo protagonista se disponía a partir hacia la India con voluntad de padecer martirio en su deseo de convertir a los no cristianos, aunque su muerte prematura lo impide.

De alguna manera, El gran príncipe de Fez lleva al presente de Calderón un conflicto y un esquema dramático que había ensayado en comedias ambientadas en los albores del cristianismo; por ello, y de igual manera, adapta a un determinado esquema literario ya utilizado por él una historia basada en acontecimientos reales. Así, la comedia no incurre en un rasgo ya advertido por Menéndez Pelayo y en el que insiste Wardropper: el anacronismo, al que el estudioso dedica especial atención en su estudio (2000, 734-738). De acuerdo con él, en estas comedias el anacronismo "forma parte de la estrategia adoptada por el dramaturgo para relacionar el tiempo pasado con el presente" $(2000,738)$, algo no necesario en Príncipe, por dramatizarse en ella sucesos contemporáneos, aunque sí podemos ver un reflejo de esta técnica en la manera que tiene Calderón de presentarnos la corte de Fez, asimilable de manera casi completa a cualquier corte cristiana: en este caso el puente que establece Calderón es más geográfico y cultural que temporal.

Wardropper atiende también a la presencia de la "ironía cósmica" en estas comedias. Así, en Mágico Justina rechaza al gentil Cipriano diciéndole "que es imposible quereros, / Cipriano, hasta la muerte" (vv. 1103-1104), rechazo que adopta un sentido diferente cuando, al final de la obra, y mientras esperan ser ejecutados, diga Justina:
Que en la muerte te querría
dije, y, pues a morir llego
contigo, Cipriano, ya
cumplí mis ofrecimientos (vv. 3048-3051).

Este tipo de ironía cósmica está también presente en Príncipe. En ella, al poco de comenzar la acción, el protagonista lee una aleya del Corán que le genera dudas:

Del imperio de Satán

- dice- solamente fueron

María y el hijo suyo

tan divinamente esentos

que no pagaron el grande

tributo del universo (p. 553). 
Entre otras cosas, reflexiona el príncipe sobre ella (las cursivas son nuestras)

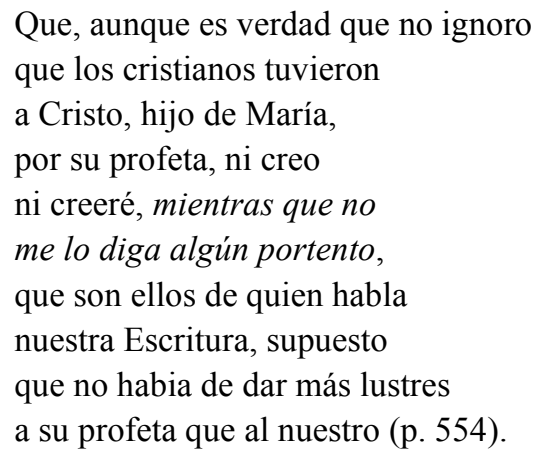

Calderón adelanta, ya al principio de la obra, prolépticamente, el lance clave del drama, que tendrá lugar al final de la segunda jornada, cuando, en medio de una tempestad en el mar, el príncipe invoque a la Virgen y esta se aparezca y calme las aguas. Así, en nueva aplicación de este principio de la ironía cósmica, será en efecto un portento el que le indique que sí es de Cristo y de María de quienes habla el texto coránico, como el propio príncipe subraya al final de la segunda jornada:

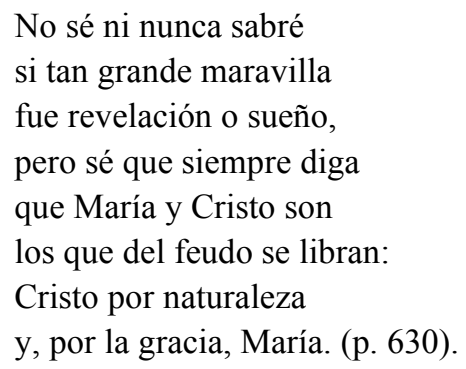

Wardropper presta atención asimismo al papel de los graciosos en estas comedias y apunta cómo "se acomodan a la conducta exigida por la sociedad en que se hallan [...]. Por eso el gracioso de la comedia religiosa es otro eslabón de la cadena que junta el pasado en que vive el protagonista santo y mártir con el presente en que vive el espectador" (pp. 741-742), y de nuevo este aserto es aplicable al moro Alcuzcuz que funciona como gracioso en Príncipe, también puente con el espectador, no tanto por motivos cronológicos, pero sí por la lejanía del espectador medio del corral de las disquisiciones teológicas del príncipe Muley. Así, si el Escarpín de Amantes, dudoso ante el aparente comportamiento del dios cristiano, dice: 


\author{
y así es bien \\ estarme como me estoy, \\ ni cristiano ni gentil, \\ sino un medio entre los dos (p. 330),
}

lo mismo dirá el también acomodaticio Alcuzcuz en Príncipe:
quedar a ser
ne crestiano por el haz
ne moro por el envés,
sino así así, entre dos luces,
cristimoro. (pp. 633-634).

Un cuarto y último recurso de estas comedias tratado por Wardropper es el de lo maravilloso cristiano, la presencia en ellas de milagros. Y de nuevo Príncipe se ajusta a él, pues la ya mencionada aparición milagrosa de la Virgen, tras una invocación del príncipe, al final de la segunda jornada, calma una tormenta, milagro que precipita la conversión del protagonista al cristianismo (pp. 629630 ). De igual manera, el intento de asesinato de este en la tercera jornada (pp. 665-670), a través de un ramillete de flores en las que se ha echado veneno, es también solventado de manera milagrosa por el príncipe, quien las huele y se frota en ellas sin que nada le suceda, lo que también provoca que los que pretendían asesinarle, o bien se conviertan al cristianismo (el moro Cide Hamet), o bien reformen su actitud (el ya cristiano Turín).

En suma, el análisis que hace Wardropper de estas comedias de "conversión de un pagano en santo cristiano" evidencia que es a este grupo al que pertenece Príncipe, pues encaja a la perfección en los diferentes aspectos tratados por Wardropper en su estudio. Para asentar aún más esta idea, analizaremos a continuación Príncipe junto con las otras obras incluidas en el grupo ya por Menéndez Pelayo para demostrar que responden a un mismo perfil y comparten un mismo esquema dramático, a pesar de las diferencias en cuanto a la ambientación. Para ello, nos serviremos del concepto de traza, acuñado por Joan Oleza, y que este define como "una combinación precisa de funciones narrativas, muchas de ellas concretadas por motivos", de manera que "el despliegue en diversos textos dramáticos de una misma traza" permite agruparlos en un "microgénero, esto es, un grupo de obras con un mismo conflicto de base" $(2009,325)$. Así, mediante el concepto de traza podemos caracterizar con eficacia este microgénero de obras ya distinguido por Menéndez Pelayo y al que ha de sumarse Príncipe, que solo se diferencia de las otras en la ambientación contemporánea y en que su protagonista no es pagano, sino musulmán. La traza podría denominarse "conversión al cristianismo de un intelectual no cristiano", y encajaría 
dentro del tipo del "convertido" analizado por Dassbach (1997, 37-51), en concreto en el tipo de conversión reflexiva y gradual. Como en el caso de Dassbach, entendemos que, para su construcción dramática, es irrelevante que el protagonista sea pagano o musulmán, ya que lo fundamental es el proceso que sigue para su conversión, común a estas obras.

Siguiendo el ejemplo de Oleza, caracterizaremos la traza a partir de una serie de funciones narrativas a las que se ajustan, total o mayoritariamente, las comedias que forman parte de ella. En esta hemos distinguido once, que son las siguientes:

1. Un pasaje de un libro hace dudar al protagonista sobre su concepto de la divinidad

2. El protagonista entra en contacto con cristianos

3. Un personaje demoníaco combate las dudas del protagonista

4. Un personaje o espíritu bueno apoya al protagonista y combate las tesis del demonio

5. El protagonista mantiene discusiones teológicas

6. Un prodigio confirma al protagonista en su deseo de conversión

7. El protagonista abandona su vida anterior para unirse a los cristianos

8. El protagonista se hace miembro de una orden

9. El protagonista es apresado

10. El protagonista participa en algún prodigio

11. El protagonista padece martirio

Estas once funciones no tienen la misma relevancia, ni aparecen en las comedias indicadas en el mismo orden. La 8, por ejemplo, afecta solo a José y a Príncipe. En la primera, Eugenia, la protagonista, tras convertirse al cristianismo, ingresa, en hábito de varón, en la orden de los eliotas (p. 212), de manera un tanto anacrónica (Wardropper 2000, 736-737). Más importante es esta función en Príncipe, pues el protagonista, Muley, ya como cristiano, decide ingresar en la Compañía de Jesús, dado su deseo de ir a convertir a gentes de otras religiones al catolicismo. Llega, además, a esta orden a través de lo que parece ser un oráculo divino (p. 663), aspecto que se amplifica en la comedia, que tiene un ingrediente destacado de glorificación de la Compañía, a la que Calderón estaba tan ligado.

Por falta de espacio, no puedo detenerme en todas estas funciones, por lo que lo haré solo en algunas especialmente significativas, entre las que podemos destacar la primera, «Un pasaje de un libro hace dudar al protagonista sobre su concepto de la divinidad». Como ya en su momento señaló Menéndez Pelayo, tal vez lo más representativo de estas comedias sea su punto de partida, 
condensado en esta primera función. Las características dudas de estos protagonistas hicieron que, de acuerdo con Silva, "the Calderonian religious drama may be called the drama of embryonic Hamlets" $(1938,180)$.

Este protagonista puede ser pagano (Mágico, José, Amantes) o musulmán (Príncipe), hombre (Amantes, Mágico, Príncipe) o mujer (José); vive en diferentes lugares (Alejandría, en José; Roma, en Amantes; Antioquía, en Mágico; Fez, en Príncipe), en los primeros siglos de la era cristiana (José, Amantes, Mágico) o en tiempos contemporáneos (Príncipe), pero es siempre un intelectual, alguien dedicado al cultivo de la filosofía, las letras y las ciencias: en Mágico ya la acotación inicial nos presenta a su protagonista, Cipriano, "vestido de estudiante"; de la de José, Eugenia, sabemos que, aun siendo mujer, lee cátedra de Filosofía en Alejandría y es de intelecto superior a cualesquiera varones de su época (p. 159); en Amantes se subraya cómo la "natural condición" de Crisanto es vivir retirado, leyendo y estudiando (pp. 241-242); en Príncipe, el protagonista, aun siendo príncipe heredero, está también inclinado a las letras y las ciencias, y es reconocido como el mayor experto en la interpretación del Corán (p. 553).

Estos personajes suelen pertenecer a las élites de sus respectivos lugares: Eugenia es hija del gobernador de Alejandría (p. 160); el padre de Crisanto es el "primer senador romano" (p. 261), que gobierna la ciudad (p. 241): en ambos casos, además, a los respectivos padres les encarga el emperador perseguir a los cristianos; Muley es el príncipe heredero de Fez. Más diluida queda en Mágico la condición social de Cipriano, de quien se indica que es estudiante y se dedica a las letras, aunque parece ser alguien reconocido en Antioquía (él mismo dice que "tengo mano tanta / en la ciudad", vv. 488-489).

Los protagonistas se nos muestran en un ambiente de estudio, rodeados de libros, ya en las acotaciones iniciales de las respectivas comedias, como la de José: "Corre una cortina y descúbrese Eugenia escribiendo en un bufete en que habrá escribanía, luces y libros" (p. 159); la de Amantes: "Córrese una cortina y está Crisanto sentado en una silla con un bufete delante; y en él, algunos libros, y lee en uno" (p. 235), o la de Príncipe: "abriéndose una tienda de campaña, se verá en ella el príncipe, vestido a lo moro, leyendo en un libro sobre un bufete en que habrá aderezo de escribir, luces y algunos instrumentos matemáticos, globos y esferas" (p. 551). En Mágico, el protagonista se nos presenta en "la amena soledad" de una "apacible estancia" (vv. 1-2), a donde se ha retirado con unos libros, huyendo de las fiestas que se celebran en la ciudad.

El pasaje que les hace dudar también suele aparecer desde el mismo inicio. En José, son los versos que empiezan la comedia, en latín, tomados de un pasaje 
de la primera epístola a los corintios de san Pablo: "Nihil est idolum in mundo, / quia nullus est Deus, nisi unus"; en Amantes proviene del evangelio de san Juan y aparece a las pocas líneas: "En el principio era el Verbo" (p. 235), y luego "El Verbo fue hecho carne" (p. 237); en Mágico esta información se dosifica: primero Cipriano, el protagonista, dice cómo la que le trae suspensa el alma es la definición de Dios que ha leído en Plinio (vv. 79-86), que no cita hasta más adelante, ya en diálogo con el demonio (vv. 169-171); en Príncipe se trata de la aleya del Corán ya citada. Es interesante notar cómo, si en José y en Amantes los que hacen dudar a los protagonistas son textos evangélicos que llegan a sus manos casualmente, en Mágico y Príncipe son obras que ya eran de referencia para los personajes: el pagano Plinio y el Corán.

Muy representativas de la traza son también las funciones 3 («Un personaje demoníaco combate las dudas del protagonista») y 4 («Un personaje o espíritu bueno apoya al protagonista y combate las tesis del demonio»), que se presentan a la vez en José, Amantes y Príncipe, en las que ambos personajes aparecen juntos. En José, "bajan de lo más alto dos sillas que tomen las dos cabeceras del bufete; en la una vendrá el Demonio, vestido de estrellas, y en la otra Eleno, viejo venerable, vestido de carmelito descalzo" (p. 161); Eugenia los ve y dialoga con ellos, que actúan como consejeros en sus dudas. En Amantes se trata de "dos voces" que oye el protagonista, "sombras sin alma y sin cuerpos / [que] a un tiempo están batallando / dentro de mi mismo pecho" (p. 238). En Príncipe, al quedarse dormido Muley "salen luchando el Buen Genio, vestido de ángel, y el Mal Genio, vestido de demonio" (p. 555). De manera similar a Amantes, ambos representan "exteriormente la lid / que arde interior en su pecho" (p. 558), según indica el Buen Genio. Pero, si en Amantes Crisanto oye estas voces y dialoga con ellas, como explica él mismo ("Dos espíritus están, / uno malo y otro bueno, / luchando dentro de mí", p. 239), no sucede así en Príncipe, donde los dos genios, aunque representen sobre el tablado y sean visibles para el espectador, no lo serán, convencionalmente, ni para el príncipe ni para los demás personajes del drama. Además, en Príncipe los dos genios tenderán a intervenir juntos, intentando influir en el protagonista; en José, sin embargo, tras su aparición inicial, tanto el demonio como Eleno tendrán papeles independientes. En el caso de Amantes, el personaje bueno se desdobla, pues, junto con el espíritu bueno que combate al malo dentro del protagonista, Crisanto acudirá a Carpoforo, maestro que se ha convertido al cristianismo (p. 239), personaje similar al Eleno de José.

La comedia más singular respecto a estas funciones es Mágico, pues en ella el demonio aparece solo y adquiere diferentes apariencias: al principio de la comedia interviene haciéndose pasar por un forastero que se ha perdido camino de 
Antioquía (vv. 93-108), y entabla conversación con Cipriano, para discutir con él la definición de Plinio que desvela al protagonista; en la segunda jornada, una vez el protagonista dice estar dispuesto a dar su alma por gozar de Justina, el demonio vuelve a aparecer, tras fingir una tormenta y el naufragio de un barco, en este caso en la apariencia de un náufrago de vida extraordinaria y que dice dominar la magia (vv. 1295-1418), lo que despierta el interés de Cipriano (vv. 1431-1432), por si también él pudiese servirse de ella para obtener sus propios fines. El supuesto náufrago se ofrece para conseguir que Cipriano, a cambio de su alma, goce de Justina (vv. 1881-1884), pues le enseñará una ciencia con la que poder atraerla a sí, lo que singulariza la acción del demonio en Mágico frente a las otras obras de la traza.

Las funciones 6 ( «Un prodigio confirma al protagonista en su deseo de conversión») y 10 («El protagonista participa en algún prodigio») están relacionadas, pues subrayan la importancia de los prodigios, de los milagros, en estos casos de conversión: las reflexiones de los protagonistas serán importantes en sus respectivos caminos de santidad, pero no suficientes, y necesitarán que un milagro les confirme cuál es la fe verdadera ${ }^{4}$.

El lugar y la relevancia de la función 6 varía de una comedia a otra. En José, al final de la primera jornada, Filipo, padre de Eugenia, quema los papeles y libros de esta para que no siga leyendo textos cristianos y abandone su vida dedicada al estudio (pp. 186-187); sin embargo, prodigiosamente vuelve a aparecer el bufete de Eugenia, con sus libros y papeles. Poco después, al principio de la segunda jornada, Eugenia se libra de ser forzada por Aurelio (que es, en realidad, el Demonio, bajo esa apariencia humana) gracias a que "Baja Eleno y arrebátala lo más veloz que pueda; abrázase con ella y vuelan" (p. 201), prodigio que se complementa con otro, no escenificado, por el que Dios concede a Eugenia el no poder ser reconocida por nadie en su nueva vida como monje eliota (pp. 211 y 219).

En Amantes, cerca del final de la primera jornada acude Crisanto junto al sabio Carpoforo, que empieza a instruirlo en la doctrina cristiana. Entonces, al venir los soldados romanos a detener al sabio, baja un ángel y "llévaselo" (p. 265), por lo que Crisanto, reprendido por su padre, pide ya el amparo del dios

4 Como explica Aparicio Maydeu (1999, 21), la comedia hagiográfica de Calderón "pretende no tanto aleccionar con el dogma como forzar a una fe visceral, la fe de la evidencia. Entiéndanse desde esta perspectiva los privilegios que adquiere en el género la tramoya y el artificio escenográfico de las apoteosis, auténtico banquete de los sentidos para un desbordamiento sensorial que dificultara cualquier razonamiento individualizado del desarrollo doctrinal de la comedia, en aras de lograr desde la escena una devoción unívoca y colectiva" (cursivas del autor). 
cristiano (p. 267). Más adelante, en la segunda jornada, para vencer la supuesta melancolía de Crisanto, Nísida canta y Cintia recita una glosa. Crisanto cree sucumbir a sus encantos y pide ayuda a Dios, que deja a las dos paralizadas. Crisanto dice para sí: "Maravillas son de un Dios / que adoro con vida y alma" (p. 302).

En Príncipe el prodigio tiene mayor relevancia. Aunque durante su estancia entre los cristianos las dudas del protagonista aumentan, tras pagarse su rescate Muley se embarca y pretende continuar su peregrinación a La Meca. Entonces se desencadena una tormenta que solo se apacigua cuando el protagonista invoca a la Virgen, que se aparece, calma la tempestad y se dirige a él, lo que hace que resuelva sus dudas y decida volver a Malta y convertirse al cristianismo (pp. 628-630).

En Mágico esta función no aparece hasta el final, cuando, al conseguir Cipriano, mediante sus artes mágicas, que Justina acuda junto a él, resulta ser esta un cadáver que se desvanece al ir a abrazarla (vv. 2525acot y 2541acot). El prodigio no servirá a Cipriano para confirmar su deseo de conversión, sino para descubrir los engaños del demonio; a continuación retomará con este una disputa en torno a los dioses que será la que le descubra al dios cristiano.

Dada su importancia, destacaré, por último, la función 11: "El protagonista padece martirio". El apresamiento al que se refiere la función 9 produce gozo entre los protagonistas y sus compañeros cristianos (José, pp. 219 y 242-243; Amantes, pp. 265 y 334; Mágico, vv. 3040-3041, 3052-3053), pues lo ven como un paso en su camino al martirio. Según señaló Silva, "Once illumined by faith the Calderonian protagonists seek nothing so ardently as to die for the Faith" $(1938,181)$. El martirio, en efecto, es asunto de importancia capital en estas comedias, ya que es el que conduce a la santidad. En José, el demonio, bajo la apariencia de Aurelio, es consciente de la situación, y se alegra al ver que Eugenia es condenada tras la acusación de Melancia:

Así de mártir

no consigue los laureles;

pues no por la fe, sinó

por un testimonio muere (p. 244).

Y por la misma razón aparece Eleno para reconvenir a Eugenia, ya que, no combatiendo una mentira evidente, "así el mérito pierdes / del martirio, no muriendo / en orden de la fe" (p. 244). Eugenia rectifica y es martirizada fuera de escena, martirio que es transmitido a los espectadores a través del relato del gracioso Capricho. La obra se cierra con su apoteosis, celebrada por la música: 
"Descúbrese en un trono de nubes Eugenia con ángeles, y va subiendo arriba" (p. 251).

En Mágico, Cipriano desea el martirio para librarse de su pacto con el demonio (vv. 2926-2927) y es ajusticiado junto con Justina. De nuevo, es un personaje el que relata la ejecución (vv. 3092-3096), aunque finalmente se descubrirá el cadalso con los cuerpos (v. 3105acot). En este caso, será el demonio, forzado por Dios, el encargado de relatar la apoteosis de ambos personajes (vv. 3106-3131).

En Amantes, Crisanto y Daría (bella joven, devota de la diosa Diana, de la que se prenda Crisanto y que irá adquiriendo protagonismo a lo largo de la comedia para acabar también convertida al cristianismo) son arrojados a una cueva, "cuyo centro / es un abismo" (p. 334), lo que genera una serie de prodigios ("toda Roma es portentos", dice Polemio, p. 335) mientras sale música de la cueva. Un ángel en una apariencia será quien explique la situación y cierre la comedia (pp. 335-336).

En Príncipe esta función queda muy subrayada. El protagonista, tras convertirse, muestra su deseo de extender la fe cristiana, sacrificando su vida al martirio (p. 649), pero muere antes de embarcarse hacia la India, por lo que el mal genio considera que no podrá gozar de él. El buen genio le contesta, sin embargo, que, "si no es mártir por sangre, / es mártir por el afecto" (p. 671), y para demostrarlo se escenifica, con gran aparato (se suprimió, de hecho, en algunos testimonios), el episodio bíblico de Abraham e Isaac, que hace reconocer al mal genio que el bueno tiene razón, por lo que Muley puede considerarse también mártir. El final de la comedia hace las veces de apoteosis, pues, tras la espectacular representación del sacrificio de Isaac, se cierra con las intervenciones de diferentes personajes, algunos aparecidos a lo largo de la comedia, otros alegóricos, como la Religión, que glosan y ensalzan distintos aspectos de la vida del príncipe, de manera que la comedia termina en un ambiente celebrativo.

Las once funciones que hemos distinguido en esta traza no implican, como es natural, que se trate de obras indistinguibles, pues todas ellas presentan diferentes variantes argumentales que las convierten en casos (Oleza 2009, 346) que singularizan la traza. Así sucede también con Príncipe, que se ajusta de manera clara, con diferentes matices, a las once funciones establecidas, lo que demuestra que es en esta traza, y no en otra, en la que debe encuadrarse; incluso hemos visto cómo Mágico, que ya Menéndez Pelayo había incluido en este grupo, parece ajustarse a menos funciones, o hacerlo de manera más particular, que la propia Príncipe, aunque no por ello haya de excluirse Mágico de la traza. La 
virgen del Sagrario y La exaltación de la cruz sí se alejan más de ella ${ }^{5}$, por lo que entendemos que es poco apropiado que junto con Príncipe establezcan un subgrupo dentro de las comedias religiosas de Calderón, pues el lugar de Príncipe es otro.

De acuerdo con Oleza, "La traza es una estructura subyacente que tiene mucho que ver con las claves ideológicas de una época" $(2009,346)$, y el aserto es perfectamente aplicable a la que acabamos de estudiar, pues, en palabras de Aparicio Maydeu $(1999,15)$, "La comedia hagiográfica barroca constituye, en manos de Calderón, un instrumento de control ideológico [...] en tanto que arma para la inspiración y el control del sentimiento religioso, máquina de la Contrarreforma". Un aspecto interesante de esta traza, y de la inclusión en ella de Príncipe, consiste en ver cómo la apología de la conversión al cristianismo no distingue de lugares ni de épocas. Entre la década de los 30 y principios de los 40 Calderón ensaya la traza en Mágico, José y Amantes ${ }^{6}$, ambientándola en el mundo pagano. Muchos años más tarde, cuando en 1669 escribe una comedia para conmemorar la muerte en Madrid de Baltasar de Loyola, acaecida dos años antes, Calderón retoma esa misma traza para aplicarla a un suceso real contemporáneo, cuyo protagonista era un príncipe musulmán. En el mundo teatral de Calderón, la conversión de este príncipe se ajustaba al mismo esquema, a la misma traza, que el de los intelectuales paganos de fondo legendario: lo fundamental era la exaltación del catolicismo como única religión verdadera.

\section{REFERENCIAS BIBLIOGRÁFICAS}

Alonso Acero, Beatriz. 2006. Sultanes de Berbería en tierras de la cristiandad: exilio musulmán, conversión y asimilación en la Monarquía hispánica (siglos XVI y XVII). Barcelona: Bellaterra.

Aparicio Maydeu, Javier. 1992. "En torno a El Joseph de las mugeres y la comedia de santos calderoniana". En La comedia de magia y de santos, editado por F.J. Blasco, E. Caldera, J. Álvarez Barrientos y R. de la Fuente, 197-205. Madrid: Júcar.

5 En La exaltación de la cruz hay algunos elementos en común con la traza, en particular a través del personaje de Anastasio (futuro san Anastasio), que pasa de sus artes mágicas al cristianismo gracias a las enseñanzas del cristiano Zacarías, pero ambos ocupan un lugar secundario en la comedia, más cercana al ambiente de guerra santa de Judas Macabeo.

6 El manuscrito autógrafo de Mágico es de 1637; con respecto a Amantes y José no hay datos seguros, pero, de acuerdo con los datos que proporciona el portal Calderón Digital, dirigido por Fausta Antonucci, Amantes podría datar de 1633-1634 o 1637-1638, y José, tal vez de 1635-1645. 
Aparicio Maydeu, Javier. 1999. Calderón y la máquina barroca: escenografia, religión y cultura en "El José de las mujeres". Amsterdam, Atlanta: Rodopi.

Calderón de la Barca, Pedro. 2009. El mágico prodigioso, editado por Natalia Fernández. Barcelona: Crítica.

Calderón de la Barca, Pedro. 2010. Los dos amantes del cielo. En Comedias, V. Verdadera quinta parte de comedias, editado por José María Ruano de la Haza, 233-336. Madrid: Biblioteca Castro.

Calderón de la Barca, Pedro. 2010. El gran príncipe de Fez. En Comedias, IV. Cuarta parte de comedias, editado por Sebastian Neumeister, 549-674. Madrid: Biblioteca Castro.

Calderón de la Barca, Pedro. 2010. El José de las mujeres. En Comedias, VI. Sexta parte de comedias, editado por José María Viña Liste, 157-252. Madrid: Biblioteca Castro.

Colombo, Emanuele. 2013. "A Muslim Turned Jesuit: Baldassarre Loyola Mandes (1631-1667)". Journal of Early Modern History 17: 479-504.

Coenen, Erik. 2009. "Las atribuciones de Vera Tassis". Castilla. Estudios de Literatura 0: 111-133.

Dassbach, Elma, 1997. La comedia hagiográfica del Siglo de Oro español: Lope de Vega, Tirso de Molina y Calderón de la Barca. New York: Peter Lang.

Menéndez Pelayo, Marcelino. 1941. Estudios y discursos de crítica histórica y literaria, vol. III, editado por Enrique Sánchez Reyes. Madrid: CSIC.

Oleza, Joan. 2009. "Trazas, funciones, motivos y casos. Elementos para el análisis del teatro barroco español". En El teatro del Siglo de Oro. Edición e interpretación, editado por Alberto Blecua, Ignacio Arellano y Guillermo Serés, 321-349. Madrid, Frankfurt am Main: Iberoamericana, Vervuert.

Silva, Ramón. 1938. "The Religious Dramas of Calderón”. Bulletin of Spanish Studies 15: 172-194.

Vega García-Luengos, Germán. 2008.“Consideraciones sobre la configuración del legado de comedias de Calderón”. Criticón 103-104: 249-271.

Wardropper, Bruce W. 2000. "Las comedias religiosas de Calderón". En Estudios sobre Calderón, tomo II, editado por Javier Aparicio Maydeu, 725-743. Madrid: Istmo.

Fernando Rodríguez-Gallego Instituto de Estudios Hispánicos en la Modernidad (IEHM) Universitat de les Illes Balears. Cra. de Valldemossa, km. 7,5 07122 Palma de Mallorca (España) https://orcid.org/0000-0002-6539-0447 
